\title{
Transmission planning for Indian power grid: a mixed integer programming approach ${ }^{\text {th }}$
}

\author{
Rajeev Chaturvedi ${ }^{1}$, Kankar Bhattacharya*, Jyoti Parikh \\ Indira Gandhi Institute of Development Research, Gen. Vidya Marg, Goregaon (East), Mumbai, 400065 India
}

\begin{abstract}
The paper presents a modeling framework to analyze some important issues associated with operation planning of a power system. Major activities involved in operations planning of large integrated power systems are considered simultaneously to ensure optimal utilization of generation and transmission capacity. The model also examines optimal transmission expansion plans vis-à-vis fuel supply issues. A mixed integer programming model is developed for this purpose and the Indian power system considered. Specific emphasis is on spatial transmission expansion plan for the existing Indian inter-state transmission grid and new transmission links, coordinated operation of the isolated regional grids and system benefits accruing from transmission expansion, enhanced fuel production and supply rescheduling to ensure efficient operation of various generating stations. (C) 1999 IFORS. Published by Elsevier Science Ltd. All rights reserved.
\end{abstract}

Keywords: Interconnected power systems; Power system economic operations and planning; Transmission planning; Mathematical programming model; India

* This paper received the Runner Up Award for "Application of Operations Research to Development" from the International Federation of Operations Research Societies (IFORS) at the 13th Triennial Conference, Vancouver, July 1996.

* Corresponding author. Current address: Chalmers University of Technology, Department of Electrical Power Engineering, 41296 Göteborg, Sweden. Tel.: + 46-31-7721651; fax: + 46-31-7721633.

E-mail address: kankar.bhattacharya@elkraft.chalmers.se (K. Bhattacharya)

${ }^{1}$ Permanent address: Reserve Bank of India, Mumbai, India 


\section{Nomenclature}

Sets

csth index for coal-based generating stationg

$g \quad$ index for grade of coal (grades G, F)

hsth index for hydro generating station

$i, j \quad$ indices for states

$k \quad$ index for the load duration curve (LDC) time-block (peak, intermediate, base)

$l \quad$ index for transmission line voltage level $(400,220$ and $132 \mathrm{kV})$

$m \quad$ index for coal mine

nsth index for central sector generating units

ncsth index for non-coal based generating station (gas, nuclear, hydro)

sth index for generating station

\section{Parameters}

$A \quad$ availability of generating unit, $\%$

$A U X$ auxiliary energy consumption in a generating station, $\%$

$C A P$ de-rated generating capacity of a station, $\mathrm{MW}$

$C F \quad$ electrical energy to heat energy conversion factor $(1 \mathrm{MWh}=857 \mathrm{Mcal})$

$C V$ calorific value of a particular grade of coal, Mcal/ton

$D E M$ energy demand in a state at a particular time-block, MW

$D T$ distance from mine to generating station, $\mathrm{km}$

$D U R$ time duration in an year, for a particular load duration time block, $\mathrm{h}$

$E \quad$ thermal efficiency of a coal-based plant, \%

EL existing inter-state tie lines

$H G$ hydro energy availability at a hydro station, in a year, MWh

$L C$ capital cost incurred in new transmission line, $\mathrm{Rs} / \mathrm{km}$

$L C A P$ power carrying capacity of an inter-state tie line for a particular voltage class, MW

$L F \quad$ transmission loss factor per unit power transfer per km line length, MWh/MWh$\mathrm{km}$

$L G T H$ length of a tie line right-of-way between two states, $\mathrm{km}$

$M C \quad$ coal mining cost, $\mathrm{Rs} /$ ton

$M C P$ annual coal production capacity of a mine, ton

Rs denotes Indian Rupees (34 Rs $\cong 1$ US\$, 1995)

$S G C$ average generation cost from non-coal based generation stations, Rs/MWh

$\mathrm{SH}$ energy share of a state from a central sector generating station

$T C$ coal transportation capacity on a particular mine-station linkage, ton

$T R C \quad$ coal transportation cost, $\mathrm{Rs} /$ ton $\mathrm{km}$

$V U$ estimated cost of unmet energy, Rs/MWh

Variables

$C$ coal supply from a mine to power station, ton

COST total system cost, Rs 
GEN energy generation from a generating station, $\mathrm{MWh}$

$N L \quad$ number of new inter-state tie lines to be commissioned

STR energy transactions between states, MWh

$U \quad$ unmet energy in a state, MWh

\section{Introduction}

Operational planning of an integrated power system involves many activities like generation scheduling and dispatch, power transmission and distribution, coordination of inter-utility transfers, appropriate tariff mechanisms, fuel production, fuel transportation planning and several others. All these activities are interdependent in the sense that they require coordination in order to achieve optimal operations and their isolated planning can lead to sub-optimal outcomes. Therefore, it is essential to take up all these interdependent activities simultaneously while carrying out any operational planning exercise for a utility.

The power sector in most developing countries have been going through similar problems like inefficient capacity utilization, high losses, demand growth far exceeding the capacity additions, unrealistic tariffs among many others. Optimal operations in coordinated manner at systems level can bring about substantial reductions in costs and other benefits. This will involve proper scheduling and utilization of existing capacities and identifying the bottlenecks in generation, transmission, fuel linkages, etc. Such coordinated operations could subsequently lead to the formation of efficient electricity power pools and spot-markets, already in existence in many developed countries.

In India, the power sector has come a long way since independence (in 1947) from small power generating stations to thermal power stations of $2000 \mathrm{MW}$ capacity and above. However, India has not been able to match its power generation requirements with the phenomenal growth of demand for electricity, presently about $8 \%$ per year. Also, the high voltage transmission network has not yet developed into a well-knit National Grid. The State Electricity Boards (SEBs) account about $60 \%$ of the total installed capacity but most of them have been incurring financial losses due to poor management of resources and administered pricing of electricity-pricing subsidies, to large group of customers (agricultural and domestic). The SEBs operate under the jurisdiction of five Regional Electricity Boards (REBs) whose role is to regulate the system operations with regard to transmission security, network stability and reliability in their respective regions through their load dispatch center and monitor inter-state and inter-regional power transfers. However, they do not have any statutory authority over the SEBs, thus making the SEBs operate virtually independent of each other.

Central sector generating stations account for about 30\% of the total installed capacity $(30,000 \mathrm{MW})$ in India, and were set up with a view to achieve economics of scale. However, they continue to allocate a fixed share of their generation to the beneficiary states without taking into consideration the growth of demand in various states over the years.

Coal is allocated to generating stations based on the recommendation of Standing Linkage Committee, which does not take into account the thermal efficiency of respective stations. Hence, cheaper generating stations are sometimes required to back down some of their units on account of insufficient availability of coal linkages. Production capacity of non-coking coal, 
which is the recommended coal in India for power generation, also creates bottlenecks in their smooth operation.

Currently there is no system of forward trading of surplus power by the SEBs and also there are no guidelines to determine the exchange prices for inter-state and inter-regional power transfers.

Transmission system expansion in India has not been consistent with the growth of demand in states, resulting in sub-optimal utilization of generation capacity. There is a need to look into inter-state and inter-regional power flows to develop suitable transmission expansion plans consistent with growing demand. Such plan should also consider augmentation of transmission capacity on existing trunks in addition to exploring new trunks to facilitate transfer of power from cheaper generating stations to bulk demand centers.

Coordinated generation scheduling to minimize system costs would involve bulk power transfer requirements from generation sites with low costs to large demand centers at distant places. Thus, transmission expansion planning is another associated issue, which needs to be addressed within the framework of utility operations planning.

In view of these, finding out suitable strategies for effective and efficient operation of the system on a country-wide scale through the formation of National Grid gathers paramount importance in view of scarcity of funds to undertake large power projects for capacity addition. The major issues related to Indian power system operations planning can be listed as follows:

- coordinated operation of the isolated regional grids

- optimal allocation of central sector generation to various SEBs

- fuel production and supply scheduling to ensure efficient operation of generating stations

- pricing strategy for inter-state and inter-regional power transfers

- spatial expansion plan for existing inter-state transmission network and new transmission links

The present work provides a modeling framework to analyze the above issues. It incorporates major activities associated with operation planning of a power system simultaneously to ensure optimal utilization of existing generation and transmission capacity. A mixed integer programming (MIP) model NATGRID-TR is developed pertaining to Indian power system planning for the purpose. This work is an extension of an earlier model-NATGRID developed by Parikh and Chattopadhyay (1996). The present model NATGRID-TR provides a framework for operations planning and transmission network expansion planning simultaneously. Another feature is that uncertainties associated with future demand and generating unit availability conditions are considered through Monte Carlo Simulation technique keeping in view the issues addressed in NATGRID. NATGRID-TR explicitly takes into consideration the new tie-line costs according to voltage class, while optimizing the total system operation costs. The proposed approach not only considers augmentation of tie lines on existing trunks, but also considers provision of new tie lines on new trunks based on the overall cost of the system.

Planning the expansion of a transmission system involves evaluating which new lines will enable the system to satisfy forthcoming loads with the required degree of reliability. Since these decisions involve considerable investment and operating costs, the planners' objective is 
to keep the present worth of all costs to the minimum. The difficulties arise due to the large number of possible alternatives, the need to make best use of information about future loads and the complexity of the reliability constraints. Outages of some specific combination of lines (highest capacity lines among them, perhaps) must not at any time overload any other line in the system.

Long-range transmission expansion planning is carried out with the assistance of network synthesis computational tools. Their objective is to determine possible alternatives while satisfying the load forecast and generation planning information. These alternatives are then subjected to reactive power planning, dynamic analysis studies, etc., in which other electrical performance criteria are taken into account.

An important class of techniques involving the digital computer in long-term planning of power systems is referred to as simulation techniques. The planner prepares load forecasts and generation requirements and then determines transmission network additions from load-flow, stability, reliability and economic studies. Alternatives that satisfy in varying degrees the above and other completely independent constraints of utility operations are investigated. The drawback of simulation techniques is that the determination of satisfactory system schedules, not to speak of optimum schedules, requires much intelligent experimentation and judgement on the part of the system planner.

Mathematical optimization techniques systematize this planning procedure and consider a great number of alternative expansion schedules. However, since the reliability constraints are formulated in terms of the entire system configuration, rather than in terms of separate system elements, their inclusion complicates the matter.

The literature on transmission planning has addressed a wide range of problems and used various methodologies to tackle them. The issues that have been of primary concern are:

- Investment decisions: This has mostly been incorporated using discrete decision variables while some of the initial works treated line additions as continuous variables and then rounded to discrete units. These decisions have also included new equipment, number of circuits, voltage level, etc.

- Operational issues: This has been addressed using ac load flow or de power flow analysis.

- Reliability and security: This has been addressed using failure probability indices, security constraints on bus voltage magnitudes, or overload network modeling.

Among some of the important work on transmission planning, Garver (1970) developed a network flow estimation technique to evaluate the overload in the network. New circuit additions are identified using a linear programming formulation of the electrical network. Kaltenbach et al. (1970) proposed a computational procedure which combined the otherwise separate activities of load flow, reliability analysis and economic evaluation. A linear flow model is first evaluated to determine the line additions, which are then subjected to reliability constraints after which investment decisions are incorporated in a dynamic programming framework. Lee et al. (1973) proposed an efficient branch-and-bound integer programming technique to solve a single-stage transmission expansion problem using a dc load flow representation. Serna et al. (1978) proposed a simulation method for the calculation of loss of load and a heuristic optimization process to choose the network reinforcements treating the system as a transportation model. Meliopoulos et al. (1982) proposed a dynamic optimization 
method by framing the problem as a discrete time optimal control problem to yield a set of cost-competitive expansion plans. Levi and Calovic (1991) have proposed a decomposition method for transmission expansion in which investment and operation decisions are obtained from different modules. Romero and Monticelli (1994) developed a hierarchical decomposition approach for three different levels of network modeling - transportation models, hybrid models and linearized power flow models, thus achieving significant reduction in investment costs. Latorre-Bayona and Perez-Arriaga (1994) proposed the minimization of global annual cost of electricity production-obtained as a sum of the annualized network investment cost, operation cost and reliability cost in a static optimization framework.

\section{The modeling framework}

The model is based on Indian power system operational data for the year 1995. The model has the following configuration:

- It incorporates $19 \mathrm{SEBs}$ of India with the exception of those in the North-East region, due to data unavailability.

- The SEBs are operationally related to four REBs of their respective regions (Eastern, Western, Northern, Southern).

- The model encompasses 268 power generation units (thermal, hydro, nuclear and gas) which are from 130 power stations and totaling an installed capacity of 75,858 MW.

- There are 106 inter-state tie lines at 400, 220 and $132 \mathrm{kV}$ level.

- Fifty-three coal mines grouped to nine major coal companies supply coal to the coal based power stations.

\subsection{Data requirements}

A large-scale model to address the range of issues as discussed in this paper, and the system configuration as given above, would understandably, have immense data requirements. Below is given a list of data requirements and configuration details for setting up the model.

\subsubsection{Systems level}

- Demand data: The model considers demand in the form of aggregated load duration curve (LDC) for each SEB, for the year under study. The LDC comprises three load blocks, peak load, intermediate load and base load.

- Existing network configuration: This requires information on all inter-state tie lines by voltage class, number and connectivity.

- Hydro station-wise energy availability: Hydro units' utilization will be governed more by, the water availability over the year, storage levels, etc., than just by the MW capacity.

- Central sector shares: These are fixed a priori for each central sector plant-how its generation would be allocated to various SEBs 


\subsubsection{Individual generating station level}

- Generator de-rated capacity: Due to partial outages, aging or other factors, the generator may be operational only up to a certain highest output level instead of its design capacity. This information is required for all generators in order to ensure the generation limits.

- Generating unit availability factor: This denotes the duration during the year for which the generator is operational (generating).

- Station auxiliary consumption: Auxiliary consumption is that component of consumption, which goes in running the generating station itself, various equipment and auxiliaries like boiler feed pumps, primary air-fans, etc. In India, this is considerably high (between 9 and $14 \%$ for coal-based units), at par with levels of inefficiencies at other points.

- Generation cost for non-coal-based units: These costs have been considered as is usual, on per KWh basis

- Thermal efficiency of coal-based units: The amount of coal consumption required to generate a unit of electricity will be dependent on this parameter. This information provides the link between the electricity module and the fuel-supply module.

\subsubsection{Fuel supply}

- Mine to coal-based power station linkages (distance, mode of transport)

- Grade of coal and production capacity of mines

- Transport capacity by mode

- Production and transport costs

All the above fuel-supply information is required to model the fuel supply linkages, production capacity constraints of mines and also to define the generation cost of coal-based generating units.

These data classifications are made in order to highlight the various levels at which the planner has to interact to obtain these information, which are not available at one single node but involve several organizations from the various SEBs, REBs, central planning authority, fuel coordination boards, etc.

\subsection{The model}

\subsubsection{Objective function}

NATGRID-TR is a single objective MIP model. The objective function represents the total system cost, which includes cost of generation, cost of unmet energy and cost of addition of new transmission lines, which is minimized subject to set of system constraints. It is important to note the representation of the cost of generation. The cost of coal-based generating units are considered to be primarily fuel-costs, and thus have two components-mining costs and transportation costs. For non-coal-based generation, a gross average cost per unit of energy generation, is considered. 


$$
\begin{aligned}
\text { Cost } & =\sum_{c s t n} \sum_{m} \sum_{g} C_{m, c s t n, g} \cdot\left[\text { TRC } \cdot D T_{m, c s t n}+M C_{m}\right]+\sum_{k} \\
& \sum_{n c s t n} G E N_{n c s t n, k} \cdot S G C_{n c s t n}+\sum_{i} \sum_{j} \sum_{l} L C_{l} \cdot L G T H_{i, j, l} \cdot N L_{i, j, l}+\sum_{i} \\
& \sum_{k} U_{i, k} \cdot V U_{k}
\end{aligned}
$$

\subsubsection{Constraints}

Demand-supply balance: This is applied to each state individually and ensures that the state's demand is met by generation from all stations within the state, central sector allocations to the state and net transfers from other states.

$$
\begin{aligned}
& \sum_{s t n} G E N_{s t n, k}\left[1-A U X_{s t n}\right]+\sum_{n s t n} G E N_{n s t n, k} \cdot\left[1-A U X_{s t n}\right] \cdot S H_{n s t n, i, k}+\sum_{l} \sum_{j} S T R_{j, i, k, l} \\
& \cdot\left[1-L F_{l} \cdot L G T H_{i, j, l}\right]-\sum_{l} \sum_{j} S T R_{i, j, k, l}+U_{i, k} \geq D E M_{i, k} \cdot D U R_{i, k}, \\
& \quad \forall \text { stn } \in i
\end{aligned}
$$

Generation capacity limits: Generation from a station is constrained by the availability (\%) of the unit, i.e., the actual running time of the generator during the period.

$$
G E N_{s t n, k} \leq A_{s t n} \cdot C A P_{s t n} \cdot D U R_{k}
$$

Central sector quota allocations: Generation from central sector generating stations is allocated to various states on a fixed quota basis.

$$
G E N_{n s t n, k} \geq \sum_{i} G E N_{n s t n, k} \cdot S H_{n s t n, i, k}
$$

Transmission capacity limits: The inter-state power transmission limits are governed by the capacity of lines which are existing, number of lines which are to be added and the voltage level of transfer.

$$
S T R_{i, j, k, l} \leq L C A P_{l} \cdot D U R_{k} \cdot\left\lfloor N L_{i, j, l}+E L_{i, j, l}\right\rfloor
$$

Integer constraint on new transmission lines: The new-line decision variable needs to be a discrete number and not be continuous. The model makes integer selections for such new line additions between states. The integer selection is obtained by various appropriate combination of the binary variables $T^{1}, T^{2}, T^{3}, T^{4}$. By appropriate combination of four binary variables $(0$ or 1$)$ a total of 15 new line addition options are available $\left(2^{4}-1=15\right)$.

$$
N L_{i, j, l}=T_{i, j, l}^{1}+2 \cdot T_{i, j, l}^{2}+4 \cdot T_{i, j, l}^{3}+8 \cdot T_{i, j, l}^{4}
$$


Calorific balance for coal based stations: This constraint ensures that the thermal efficiency considerations are taken care of, i.e. the coal based generation is translated to the equivalent calorific input that is required, based on the generator's heat rate characteristic.

$$
\sum_{m} \sum_{g} C_{m, c s t n, g} \cdot E_{c s t n} \cdot C V_{g}=\sum_{k} G E N_{c s t n, k} \cdot C F
$$

Coal production capacity constraint: The gross coal consumption by different power stations fed by a common mine will be constrained by the coal production capacity of the mine during the year.

$$
\sum_{c s t n} \sum_{g} C_{m, c s t n, g} \leq M C P_{m}
$$

Coal transportation capacity constraint: The coal consumption at a power station will be constrained by the transportation linkages and capacity by a particular mode (rail, road, etc.) from the mine to this station.

$$
\sum_{g} C_{m, c s t n, g} \leq T C_{m, c s t n}
$$

Hydro energy constraint: Hydro generation will be restricted by water storage available over the year.

$$
\sum_{k} G E N_{h s t n, k} \leq H G_{h s t n}
$$

2.2.2.1. Monte Carlo simulation of NATGRID-TR. Monte Carlo simulation is used to model the uncertainty associated with operation of integrated power systems. If the distribution form of the uncertain parameters of the system is known, the expected behavior of the system can be studied by averaging the outcomes of different simulation cases. Among the advantages of Monte Carlo simulation is its conceptual simplicity, i.e., each simulation exercise (or sampling) can be viewed as a possible state of system operation.

In this work, the demand at each state and availability of each generator are treated as uncertain parameters and have been assigned a range of variation for each. Using uniform random number generator, numerous simulations are carried out over the specified range of uncertainties and the expected outcomes are evaluated by averaging over the entire simulation samples. The expected values of system parameters can be considered for operational planning of the system.

\section{Scenarios and simulation}

The NATGRID-TR model is developed in GAMS (Generalized Algebraic Modeling Systems) platform and the MIP formulation is solved using branch and bound algorithm on 
XA10.0 (Extended Algorithm) solver (GAMS Release 2.25). The existing grid configuration showing inter-state tie lines at various voltage levels is given in Fig. 1. The names of various states shown on the maps are abbreviated versions. The states' names are given in Appendix. Due to the large number of new line selection possibilities (each of the 19 SEBs could connect in various combinations, 3 voltage levels, 4 binary variables) the number of integer variables would be unmanageably large. For one SEB, the number of integer choices would be, $3 \times 4 \times\left({ }^{18} C_{1}+{ }^{18} C_{2}+\cdots+{ }^{18} C_{18}\right)$. To circumvent this problem of handling numerous integer variables, many of them being unnecessary, it is logical to apply a planners' perspective about feasible line additions. For example, it would be impractical from technological considerations

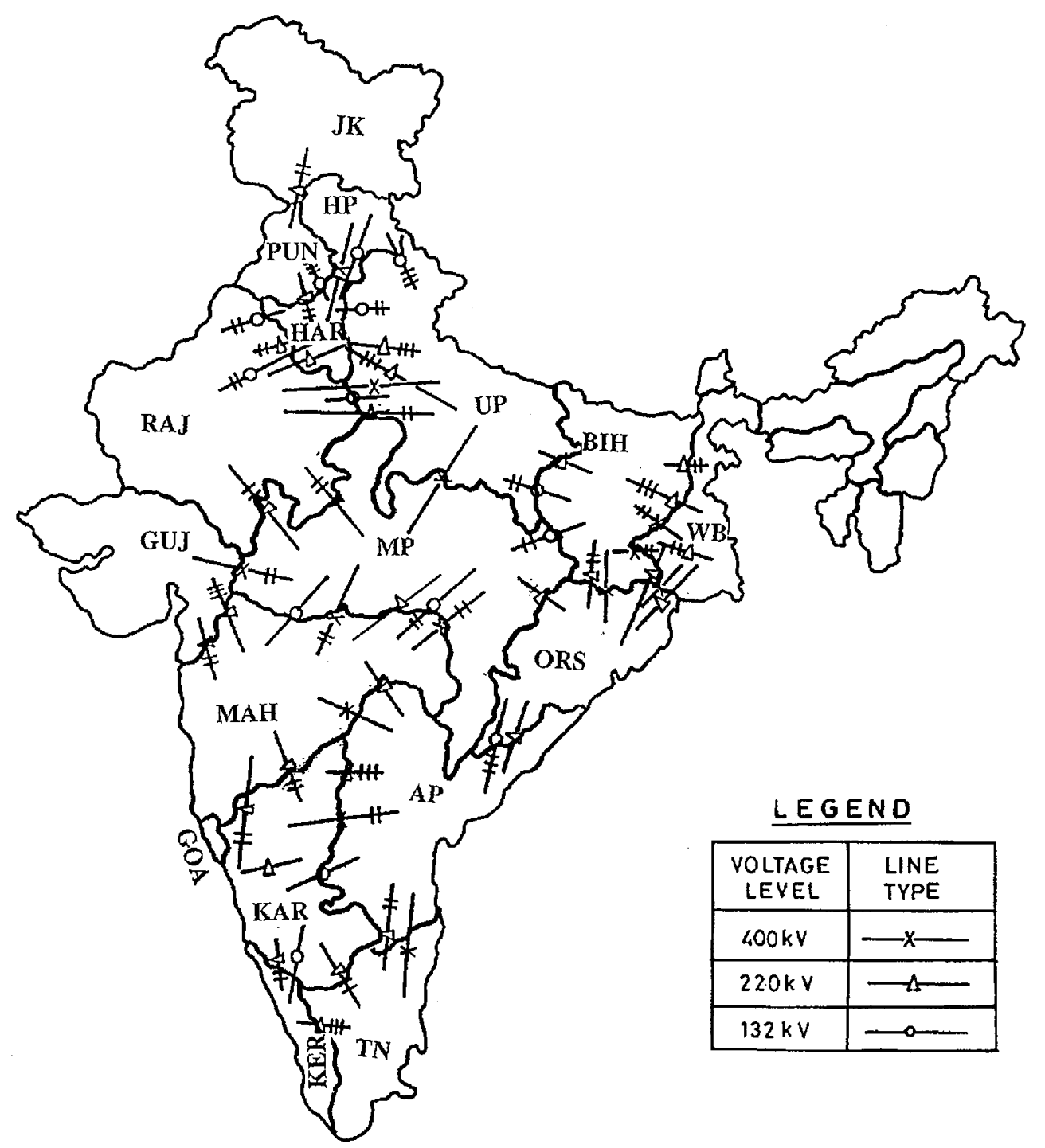

Fig. 1. Existing inter-state tie-lines. 
to set up a transmission line between MAH and WB (Fig. 1). Therefore, a feasibility set for new line addition is defined for each of the member SEBs and the new line selection is restricted within this set. Table 1 gives the feasibility set of new line additions, used for this study.

The model thus formulated, has the following computational dimensions:

Objective function $=1$

Number of Constraints $=3225$

Number of Variables $=13510$

Number of Integer Variables $=4140$

Two scenarios are constructed to examine the various aspects of operations planning and analyze the model simulation outcome.

- Optimal operation $(O P T)$ : This scenario simulates the system operation based on the least cost criterion. Generation scheduling, transmission line addition decisions, etc. are obtained so as to minimize the total objective function subject to the constraints on fuel supply and transportation.

- Coal supply relaxed (CRELX): This scenario examines the system operation when fuel supply bottlenecks are removed. This is a relaxed case where it is inherently assumed that fuel is available without any limits.

Table 1

Feasibility set for new line additions

\begin{tabular}{ll}
\hline Member SEB & Feasibility set \\
\hline DEL & RAJ, UP, HAR \\
HAR & HP, PUN, RAJ, UP, DEL \\
HP & HAR, PUN, UP, JK \\
JK & PUN, HP \\
PUN & HAR, HP, JK, UP, RAJ \\
RAJ & HAR, DEL, UP, PUN, MP, GUJ \\
UP & HAR, HP, DEL, RAJ, BIH, MP, PUN \\
GOA & MAH, KAR \\
GUJ & MAH, MP, RAJ \\
MP & MAH, RAJ, UP, ORS, AP, GUJ, BIH \\
MAH & GUJ, MP, GOA, KAR, AP \\
AP & KAR, TN, MP, ORS, MAH \\
KAR & AP, KER, TN, MAH, GOA \\
KER & KAR, TN \\
TN & KAR, KER, AP \\
BIH & ORS, DVC, WB, UP, MP \\
ORS & BIH, WB, MP, AP, DVC \\
DVC & BIH, WB, ORS \\
WB & BIH, ORS, DVC \\
\hline
\end{tabular}




\subsection{Results and discussion}

The two scenarios described earlier are examined for two different network configurations:

- with existing transmission network

- with expanded transmission network

Table 2 provides a comparison of the different parameters for all the above scenarios. A summary of important findings from the simulation of scenarios are given below.

\subsubsection{With existing grid (transmission expansion not considered)}

\subsubsection{OPT scenario}

- There is a significant amount of unmet energy in the system, in spite of the optimal generation scheduling plan. $37 \%$ of the total system cost is accounted for by unmet energy costs.

- Coal-based generation accounts for the bulk of the supply with not much flexibility in the operation of nuclear units, while hydro generation is utilized as per the water availability and mostly scheduled during peak and inter. Costly gas-based units serve the peak load.

\subsubsection{OPT vis-à-vis CRELX scenario}

- The total system cost reduces by 33\% when coal supply constraints are removed (CRELX). This is primarily due to the reduction in unmet energy.

- Unmet energy reduces by almost $80 \%$ when coal supply bottlenecks are removed.

- With increased coal availability (CRELX), costly gas-based generation is substituted by

Table 2

Comparison of aggregate system parameters ${ }^{\mathrm{a}}$

\begin{tabular}{lcrrr}
\hline & \multicolumn{2}{c}{ Existing grid } & \multicolumn{2}{c}{ Expanded grid } \\
\cline { 2 - 5 } & \multicolumn{1}{c}{ OPT } & CRELX & OPT & CRELX \\
\hline Total system cost, billion Rs & 123.69 & 82.61 & 112.29 & 82.86 \\
$\quad$ Generation cost, billion Rs & 77.45 & 73.24 & 88.1 & 71.46 \\
New tie line cost, billion Rs & - & - & 15.0 & 11 \\
$\quad$ Unmet energy cost, billion Rs & 46.24 & 9.37 & 9.19 & 0.404 \\
Total generation, billion kWh & 414.77 & 436.13 & 433.81 & 439.0 \\
$\quad$ Hydro, billion kWh & 74.47 & 74.47 & 74.47 & 74.47 \\
Gas, billion kWh & 31.45 & 28.52 & 31.87 & 24.84 \\
Coal, billion kWh & 295.47 & 319.76 & 314.09 & 326.31 \\
Nuclear, billion kWh & 13.38 & 13.38 & 13.38 & 13.38 \\
Unmet energy, billion kWh & 23.2 & 4.68 & 4.6 & 0.202 \\
Inter-state energy transfers, billion kWh & 38.42 & 60.72 & 92.56 & 86.66 \\
Coal consumption, million tons & 210.52 & 245.88 & 219.06 & 249.78 \\
\hline
\end{tabular}

\footnotetext{
a 34 Rs $=1$ US\$ (1995).
} 
cheaper coal-based generation. This is the second factor after unmet energy, which contributes to cost reduction in CRELX.

- Inter-state energy transfers increase substantially. This is because of bulk energy transfers from cheaper coal-based generation in one state to large demands in other states.

- Coal consumption increases by $17 \%$ in CRELX, which however, is of environmental concern because of the poor grades of coal used in India.

\subsubsection{With expanded grid (transmission expansion considered)}

\subsubsection{Existing grid vis-à-vis expanded grid: OPT scenario}

- The total system costs are reduced by $9 \%$ in expanded grid (OPT) from existing grid (OPT) due to a substantial reduction in unmet energy in the system.

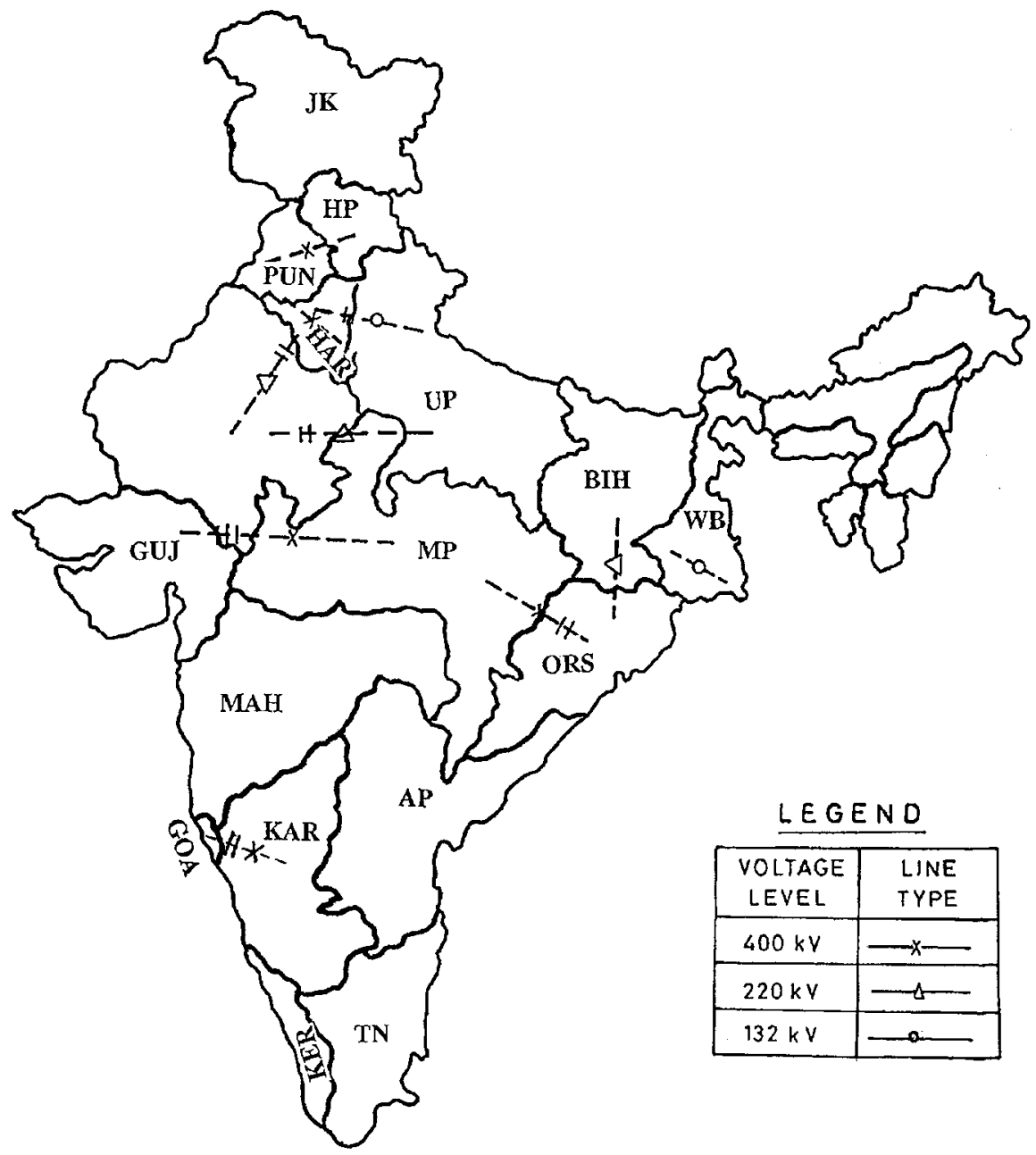

Fig. 2. New lines identified in 'OPT' scenario. 
- The reduction in unmet energy is due to increased energy transfers on new lines, which in turn call for increased power generation in the system by $4.6 \%$. This was the extent of transmission bottlenecks, which was present in the system.

- Most of the increased generation comes from coal-based units, which does have the capacity and margins, but have to operate under bottlenecks of either transmission or coal supply. The other types of generators do not have much flexibility in operations, if least-cost operation is the criterion.

\subsubsection{OPT vis-à-vis CRELX}

- Total system costs are further reduced by $26 \%$ when coal supply bottlenecks are removed with transmission expansion. This is due to further reduction in unmet energy.

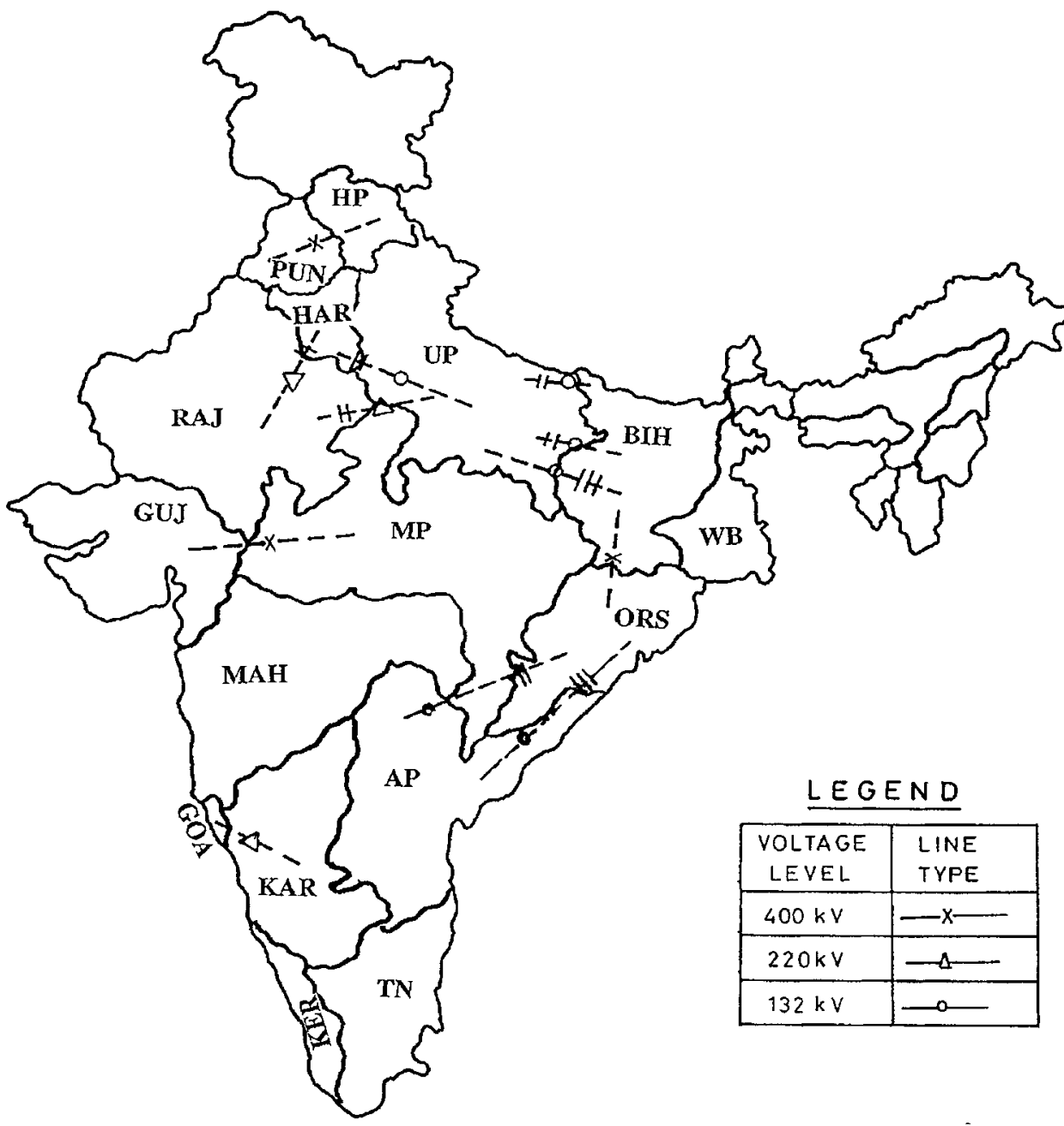

Fig. 3. New lines identified in 'CRELX' scenario. 
- Transmission expansion requirements are somewhat less with increased coal supply. This implies that with more coal availability, some of the states' demands can be met by increased generation from local units.

- Inter-state energy transfers will thus reduce to some extent compared to the OPT scenario.

Figs. 2 and 3 shows the new inter-state transmission lines identified in OPT and CRELX scenarios, respectively, for different voltage levels. An important difference between them is, CRELX identifies more line selections from BIH and ORS, the states where major coal mines are located.

Table 3 lists the new transmission line selections in the two scenarios, as depicted in Figs. 2 and 3 .

\subsection{Cost of power supply}

Dual of the demand-supply constraint (Eq. 2) gives the short run marginal cost (SRMC) of supplying power at a state. Fig. 4 shows the SRMC in the OPT scenario with existing grid, at different states. The variation in SRMC over different time blocks correspond to the demand variations, i.e. it is high during peak and low during base load. This strengthens the logic of introducing time-of-day prices in inter-state power transactions. The SRMC also varies considerably across states. This justifies a case for pricing to recover the SRMC of the state exporting power from the power importing state. It is also to be noted that, when the marginal cost of supply at any state is Rs.2000/MWh, which is the cost of unmet energy considered in the model, it means that the state has unmet energy during that period.

With the same grid configuration and coal supply constraints removed (i.e. in CRELX scenario), the base-SRMC at some states reduce considerably e.g. DEL, HAR, PUN, UP, GUJ, KAR, TN and BIH (Fig. 5). This implies that increased coal-supply could reduce some

Table 3

Proposed inter-state tie lines

\begin{tabular}{|c|c|c|c|c|c|c|}
\hline & \multicolumn{3}{|c|}{ OPT scenario } & \multicolumn{3}{|c|}{ CRELX scenario } \\
\hline & $400 \mathrm{kV}$ & $220 \mathrm{kV}$ & $132 \mathrm{kV}$ & $400 \mathrm{kV}$ & $220 \mathrm{kV}$ & $132 \mathrm{kV}$ \\
\hline DEL-HAR & 1 & - & - & - & - & - \\
\hline HP-PUN & 1 & - & - & 1 & - & - \\
\hline RAJ-HAR & - & 2 & - & - & 2 & - \\
\hline UP-HAR & - & - & 2 & - & - & 2 \\
\hline UP-RAJ & - & 2 & - & - & 2 & - \\
\hline GOA-KAR & 2 & - & - & - & 1 & - \\
\hline GUJ-MP & 3 & - & - & 1 & - & - \\
\hline BIH-UP & - & - & - & - & - & 7 \\
\hline MP_ORS & 2 & - & - & - & - & - \\
\hline ORS-AP & - & - & - & - & - & 5 \\
\hline BIH-ORS & - & 1 & - & 1 & - & - \\
\hline WB-DVC & - & - & 1 & - & - & - \\
\hline
\end{tabular}




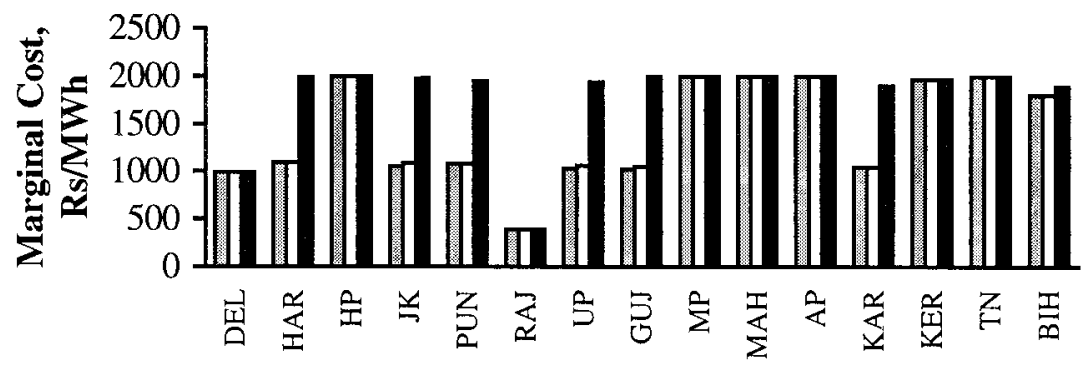

States

\section{पBASE DINTER ם PEAK}

Fig. 4. Marginal cost of supply with existing grid (OPT scenario).

unmet energy during the base hours, though the peak and inter- unmet energy is almost unchanged. This means that the system is capacity constrained and even with removal of coal constraint, there is peak energy shortage in most states.

Figs. 6 and 7 shows the SRMC with expanded grid for OPT and CRELX scenario respectively. It is found that with transmission expansion, the SRMC for inter is reduced substantially both without and with coal-supply relaxation. However, the peak SRMC continues to be at Rs.2000/MWh for most states thereby indicating capacity shortages during peak and this needs to be addressed through generation capacity additions.

\section{Conclusion}

The present study carried out in the Indian context shows that optimal generation scheduling, suitable transmission line expansion strategies, streamlining of fuel supply schedules

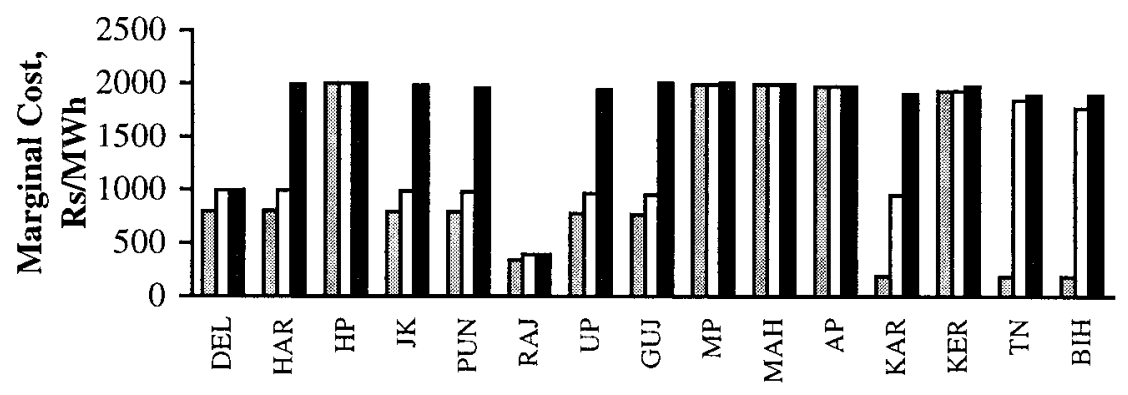

States

$\square$ BASE DINTER DPEAK

Fig. 5. Marginal cost of supply with existing grid (CRELX scenario). 


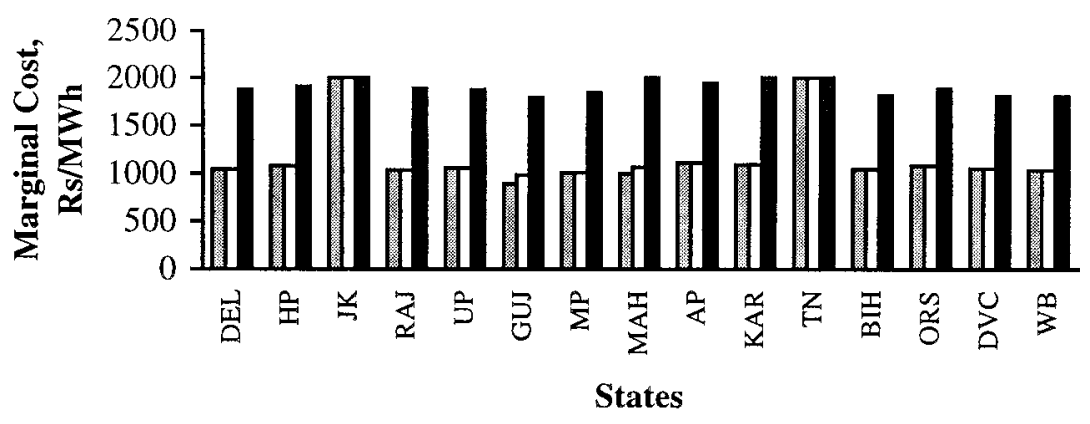

\section{BASE DINTER E PEAK}

Fig. 6. Marginal cost of supply with expanded grid (OPT scenario).

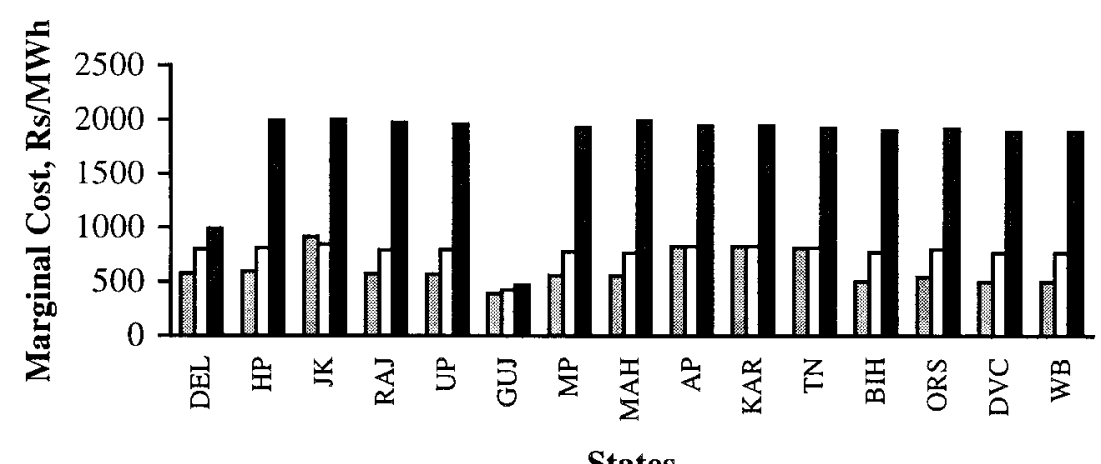

States

\section{$\square$ BASE DINTER — PEAK}

Fig. 7. Marginal cost of supply with expanded grid (CRELX scenario).

and proper pricing policies can substantially reduce the system costs, unmet energy in the system and the growing need for capacity addition. Coordinated grid operation ensures effective and efficient utilization of existing generation facilities.

A mixed integer programming model is developed for the purpose, incorporating several features of large interconnected power system operation planning. The model incorporates several issues of Indian power system, and addresses some of the issues therein.

\section{Appendix A}

Following is a list of abbreviated State-names used in the paper:

HP Himachal Pradesh

BIH Bihar 


$\begin{array}{ll}\text { PUN } & \text { Punjab } \\ \text { WB } & \text { West Bengal } \\ \text { HAR } & \text { Haryana } \\ \text { ORS } & \text { Orissa } \\ \text { UP } & \text { Uttar Pradesh } \\ \text { MP } & \text { Madhya Pradesh } \\ \text { RAJ } & \text { Rajasthan } \\ \text { GUJ } & \text { Gujarat } \\ \text { MAH } & \text { Maharashtra } \\ \text { KAR } & \text { Karnataka } \\ \text { TN } & \text { Tamil Nadu } \\ \text { AP } & \text { Andhra Pradesh } \\ \text { KER } & \text { Kerala } \\ \text { JK } & \text { Jammu Kashmir } \\ \text { GOA } & \text { Goa } \\ \text { DEL } & \text { Delhi } \\ \text { DVC } & \text { Damodar Valley Corporation }\end{array}$

(DVC is an independent utility supplying power to the western-WB and south-BIH region. It has not been shown as a state, therefore. Those inter-state transmission connections lying wholly within WB i.e. WB-WB are those connections involving DVC).

\section{References}

Parikh, J., Chattopadhyay, D., 1996. A multi-area linear programming model for analysis of economic operation of Indian power system. IEEE Transactions on Power Systems PWRS-11, 52-58.

Garver, L.L., 1970. Transmission network estimation using linear programming. IEEE Transactions on Power Apparatus and Systems PAS-89, 1688-1696.

Kaltenbach, J.-C., Peschon, J., Gehrig, E.H., 1970. A mathematical optimization technique for expansion of electric power transmission systems. IEEE Transactions on Power Apparatus and Systems PAS-89, 113-119.

Lee, S.T.Y., Hicks, K.L., Esteban, H., 1973. Transmission expansion by branch and bound integer programming with optimal cost capacity curves. IEEE Transactions on Power Apparatus and Systems PAS-93, 1390-1400.

Serna, C., Duran, J., Camargo, A., 1978. A model for expansion planning of transmission systems: a practical example. IEEE Transactions on Power Apparatus and Systems PAS-97, 610-615.

Meliopoulos, A.P., Webb, R.P., Bennon, R.J., Juves, J.A., 1982. Optimal long-range transmission planning with AC load flow. IEEE Transactions on Power Apparatus and Systems PAS-101, 4156-4163.

Levi, V.A., Calovic, M.S., 1991. Linear programming based decomposition method for optimal planning of transmission network investments. IEEE Transactions on Power Systems PWRS-6, 937-943.

Romero, R., Monticelli, A., 1994. A hierarchical decomposition approach for transmission network expansion planning. IEEE Transactions on Power Systems PWRS-9, 373-380.

Latorre-Bayona, G., Perez-Arriaga, J.I., 1994. Chopin: a heuristic model for long-term transmission expansion planning. IEEE Transactions on Power Systems PWRS-9, 1-9.

GAMS Release 2.25, A User's Guide, GAMS Development Corporation. 